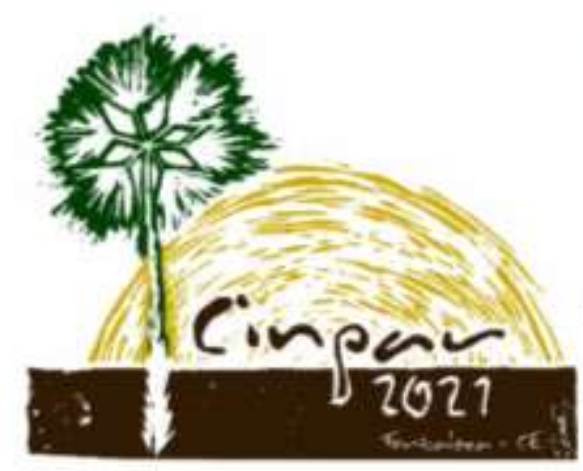

XVII Congresso Internacional sobre Patologia e Reabilitação das Construçōes

XVII Congreso Internacional sobre Patologia y Rehabilitación de las Construcciones

XVII International Conference on Pathology and Constructions Rehabilitation

FORTALEZA (Brasil), 3 a 5 de junho de 2021 https://doi.org/10.4322/CINPAR.2021.072

\title{
Panorama da Manutenção Predial em Edifícios Residenciais de Fortaleza - CE
}

\section{Panorama of Building Maintenance in Residential Buildings from Fortaleza-CE.}

\author{
Eric Costa Campelo ${ }^{1}$, Marisa Teófilo Leitão ${ }^{2}$ \\ ${ }^{1}$ Centro Universitário Christus (Unichristus), Fortaleza - CE, Brasil, campelo.eric94@hotmail.com \\ ${ }^{2}$ Centro Universitário Christus (Unichristus), Fortaleza - CE, Brasil, marisaleitao43@gmail.com
}

\begin{abstract}
Resumo: Em todas as edificações ocorre o processo natural de envelhecimento, que pode ser acelerado pela falta de manutenção e acarretar nas manifestações patológicas. As manifestações patológicas aparecem na edificação indicando que algo no sistema necessita de reparos. Essas manifestações geralmente ocorrem por meio de erros na execução de obra ou por falta de manutenção por parte do usuário da edificação. Para identificar tais manifestações utiliza-se a inspeção predial, que acarreta a liberação de um laudo de inspeção. Em seguida ocorre a etapa de execução da reforma a fim de solucionar os problemas. Todo esse processo é melhor detalhado nas normas de gerenciamento e manutenção predial que formam um ciclo de dependência entre si. Essas normas são a NBR 14037 (ABNT, 2011); NBR 5674 (ABNT, 2012); NBR 15575(ABNT, 2013); e por último a NBR 16280 (ABNT, 2015). Diante disso, o presente trabalho busca esclarecer características tanto das normas como dos termos inerentes as mesmas, sendo o objetivo apresentar um panorama das práticas de manutenção predial seguidas por edifícios residenciais em Fortaleza - CE. Para tanto, serão aplicados questionários às administrações de edifícios residenciais em Fortaleza - CE assim como entrevista com empresas de inspeção predial mostrando qual das partes necessitam rever seus métodos de trabalho para solucionar e evitar problemas visto na análise das respostas. O resultado encontrado foi que os síndicos, assim como os condôminos, possuem a tendência de negligenciar problemas nas edificações, a maioria não recebe manual das edificações e geralmente contratam profissionais não habilitados para diversos serviços na edificação, somente chamando o profissional habilitado para grandes problemas como estruturais.
\end{abstract}

Palavras-chave: Manifestações Patologicas. Normas Técnicas. Inspeção Predial. Vida Útil. Manutenção Predial.

ABSTRACT: In all buildings the natural aging process occurs, which can be accelerated by lack of maintenance and lead to pathological manifestations. Pathological manifestations appear in the building indicating that something in the system needs repair. These manifestations usually occur through errors in the execution of the work or due to lack of maintenance on the part of the building user. To identify such manifestations, building inspection is used, which results in the release of an inspection report. Then there is the stage of implementing the reform in order to solve the problems. This whole process is better detailed in the building management and maintenance standards that form a cycle of dependence on each other. These standards are NBR 14037 (ABNT, 2011); NBR 5674 (ABNT, 2012); NBR 15575 (ABNT, 2013); and finally NBR 16280 (ABNT, 2015). In view of this, the present work seeks to clarify characteristics of both the rules and the terms inherent to them, with the objective of presenting an overview of building maintenance practices followed by residential buildings in Fortaleza - CE. To this end, questionnaires will be applied to the administrations of residential buildings in Fortaleza - $\mathrm{CE}$, as well as interviews with building inspection companies showing which of the parties need to review their working methods to solve and avoid problems seen in the analysis of the 
responses. The result found was that the liquidators, as well as the tenants, have a tendency to neglect building problems, most do not receive a building manual and generally hire professionals not qualified for various services in the building, only calling the qualified professional for major problems such as structural.

Keywords: Pathologies. Technical Standards. Building Inspection. Lifespan. Building maintenance.

\section{Introdução}

A alta demanda imposta no mercado imobiliário para a construção de edifícios tem obrigado as construtoras operarem com menores custos e com a mesma eficiência, o que pode ocasionar erros de projeto e acidentes de trabalho, por isso a importância da padronização dessas obras por meio das Normas Brasileiras de Regulamentação (NBR).

As NBR's estabelecem padrões de desempenho e execução, tendo como objetivo garantir a segurança do consumidor em relação ao produto entregue. Existem quatro normas de regulamentação que formam um ciclo na área de gerenciamento e manutenção predial, sendo essas normas: NBR 14037: Manual de Uso, Operação e Manutenção (ABNT, 2011); NBR 5674: Manutenção de edificações - Requisitos para o sistema de gestão de manutenção (ABNT, 2012); NBR 15575: Edificações habitacionais - Desempenho (ABNT, 2013) e por último NBR 16280: Reforma em edificações - Sistema de gestão de reformas - Requisitos (ABNT, 2015) (PILZ, 2019, p. 3).

A preocupação com a manutenção das edificações tem crescido na construção civil devido ao grande número de acidentes ocorridos nos últimos anos envolvendo edificações já com um determinado tempo de uso. De acordo com Sancho (2018) alguns dos acidentes ocorridos recentemente foram: o desabamento do Edifício Liberdade (Rio de Janeiro, 2012), o desabamento da varanda do Edifício Versailles (Fortaleza, 2016). O mais recente desses acidentes ocorreu com o desabamento do Edifício Andrea (Fortaleza, 2019).

Quando se fala de manutenção predial pode-se ainda relacionar a mesma com a vida útil da edificação. Para Possan e Demoliner (2013) vida útil compreende o período de início de uso da edificação até o momento que deixa de atender o usuário. Ainda segundo a mesma autora, caso a manutenção seja realizada no período adequado, isso resultará no prolongamento da vida útil da edificação.

Segundo Sancho (2018) para determinar o grau de degradação da edificação utiliza-se a inspeção predial, que tem como função determinar as falhas existentes, escolher a melhor forma para a correção desses problemas e criar um plano de prevenção com a manutenção preventiva. Segundo Cavalcante (2019) a inspeção predial era pouco relevante para os gestores de imóveis, sendo que recentemente houveram muitos acidentes envolvendo edifícios residenciais o que fez essa atenção aumentar.

A partir da discussão cada vez mais crescente sobre a importância da manuetnção de edificações, a presente pesquisa tem como objetivo geral apresentar um panorama das práticas de manutenção predial seguidas por edifícios residenciais localizados na Regional II da cidade de Fortaleza - CE. Com o intuito de atender a este objetivo geral, foram definidos como objetivos específicos identificar a existência do plano de manutenção e do manual do proprietário em edifícios residenciais, identificar as manifestações patológicas recorrentes nas inspeções prediais e por último verificar a relação das manifstações patológicas recorrentes com a deficiência na manutenção.

\section{Metodologia}

Definiu-se no início da pesquisa analisar apenas edifícios residenciais e que estejam localizados em bairros inseridos na Regional II da cidade de Fortaleza - CE. A coleta de dados foi realizada por meio de aplicação de questionário com os sindicos de edifícios residenciais da cidade de Fortaleza - $\mathrm{CE}$, utilizando como ferramenta "Google Forms".

A fim de complementar as informações obtidas por meio dos questionários aplicados aos sindícos dos edifícios, foi também aplicada uma entrevista a empresas que prestam serviço de inspeção predial. A entrevista aconteceu por meio de vídeo conferência e teve um caráter semiestruturado. 
As perguntas do questionário aplicado ao síndicos dos edifícios e da entrevista com as empresas de inspeção predial foram baseadas nas normas: NBR 14037: Manual de Uso, Operação e Manutenção (ABNT, 2011); NBR 5674: Manutenção de edificações - Requisitos para o sistema de gestão de manutenção (ABNT, 2012); NBR 15575: Edificações habitacionais - Desempenho (ABNT, 2013) e por último NBR 16280: Reforma em edificações - Sistema de gestão de reformas - Requisitos (ABNT, 2015). Quanto aos dados obtidos tanto nas entrevistas como dos questionários, foram analisados e relacionados de forma a responder os objetivos da presente pesquisa.

\section{Resultados}

\section{1 - Repostas questionário aplicado aos síndicos}

Inicialmente foi aplicado um questionário a síndicos de condomínios da cidade de Fortaleza - CE. O questionário foi divulgado em grupos de síndicos, empresas de administração de condomínio entre outros por meio de aplicativos de mensagens. Foram obtidas trinta e seis respostas no período de 02 de outubro a 02 de novembro de 2020. A primeira parte do questionário teve como objetivo fazer uma caracterização dos condomínios respondentes. Nesta caracterização foi observado a tendência das edificações possuirem idade entre 15 e 30 anos. Outras informações obtidas por meio da caracterização mostram que as edificações participantes, em sua maioria, possuem: mais de 10 andares e 2 apartamentos por andar; equipamentos de lazer como salão de festas, piscina, quadra e playground; e encontram-se em bairros nobres da cidade de Fortaleza - CE com IDH superior a 0,7 conforme anuário do Ceará 2019-2020. Tais dados levam a traçar um perfil de edifícios de médio a alto padrão.

Em seguida foi questionado sobre a edificação possuir o manual de manutenção, com a maioria das respostas indicando não, conforme o Gráfico 1. Observando as respostas de caracterização das edificações, as mesmas foram entregues em data anterior a vigência da norma (edificações com idade entre 15 e 30 anos) e isso pode explicar o fato de muitos condomínios não possuírem o manual do condomínio.

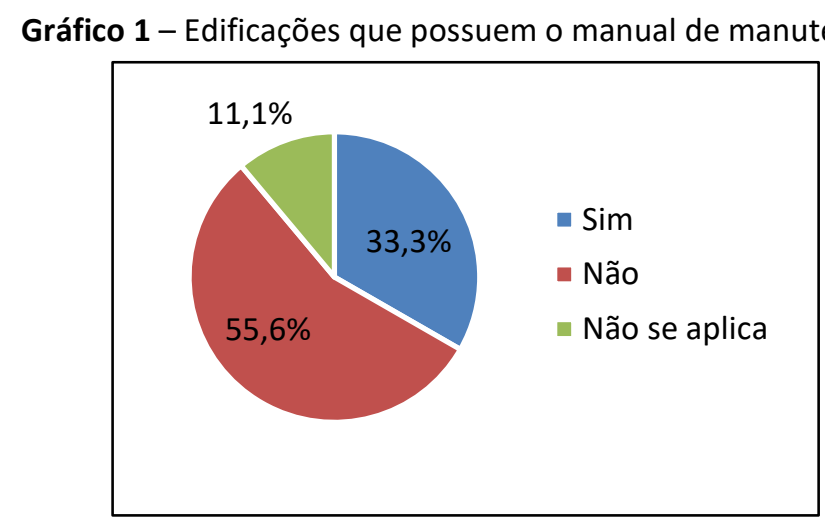

Posteriormente questionou-se sobre a prática de contratação de um responsável técnico para reformas nas áreas comuns, com a maioria dos síndicos marcando sim, porém um número significativo marcando não, em torno de $39 \%$, conforme o Gráfico 2. É possível verificar com frequência situações em que o síndico da edificação é uma pessoa que não possui formação técnica e portanto não tem conhecimento das normas em vigor e tão pouco dos possíveis acidentes que a edificação fica quando são realizadas reformas sem acompanhamento técnico. Intervenções irregulares na estrutura por exemplo podem ocasionar prejuízos irreparáveis e danos físicos aos usuários. Dessa forma, é imprescindível a contratação de profissionais habilitados para realizar reparos e manutenções em edificações. 
Gráfico 2 - Edificações que contratam responsável técnico para reformas

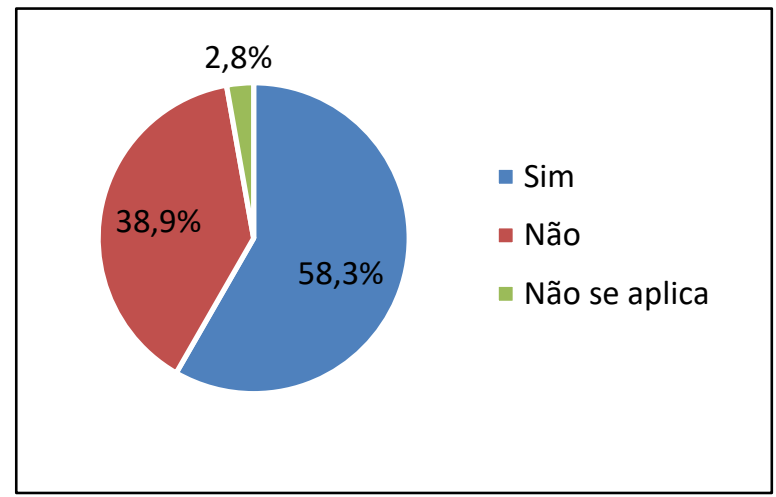

Questionou-se ainda se as edificações solicitam aos moradores algum documento para reformas nas unidades habitacionais, com a maioria dos síndicos marcando não, em torno de 55\%, conforme o Gráfico 3 . Sabe-se que segundo legislação é imprescindível que reformas nas unidades privadas sejam acompanhadas por profissional habilitado e seja realizado o registro de anotação técnica. Isso deve ser exigido pela administração do condomínio de forma a evitar que sejam realizadas reformas que prejudiquem a estrutura da edificação.

Gráfico 3 - Edificações que solicitam aos moradores documentos para reformas habitacionais

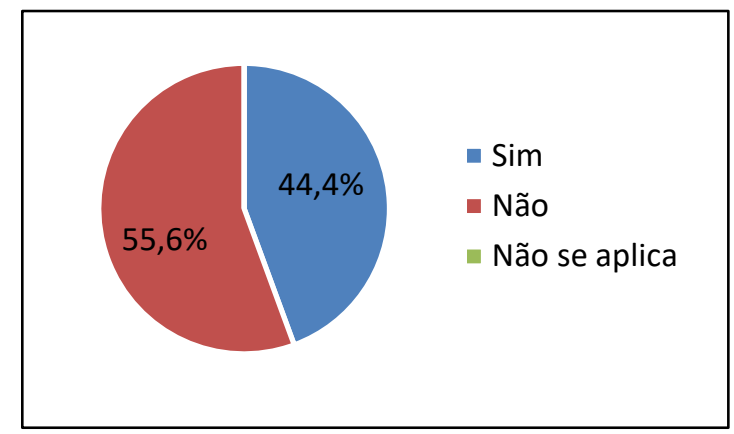

A pergunta seguinte questionou sobre quais os sistemas da edificação que possuem manutenção periódica, a fim de receber as mais variadas respostas, essa pergunta foi feita de forma aberta, e as respostas mais repetidas foram sistemas de elevadores, de bombas, geradores, reservatórios de água, SPDA, conforme Gráfico 4. Uma das respostas chamou bastante atenção, onde o entrevistado escreveu: "Não possui manutenção periódica. Apenas quando necessário, como piso de garagem, fachadas". É importante observar que a estrutura, as fachadas e instalações elétricas não foram mencionadas. E estes são sistemas dentro de uma edificação que apresentam problemas corriqueiramente.

Gráfico 4 - Elementos da edificação que o síndico realiza a manutenção periódica 


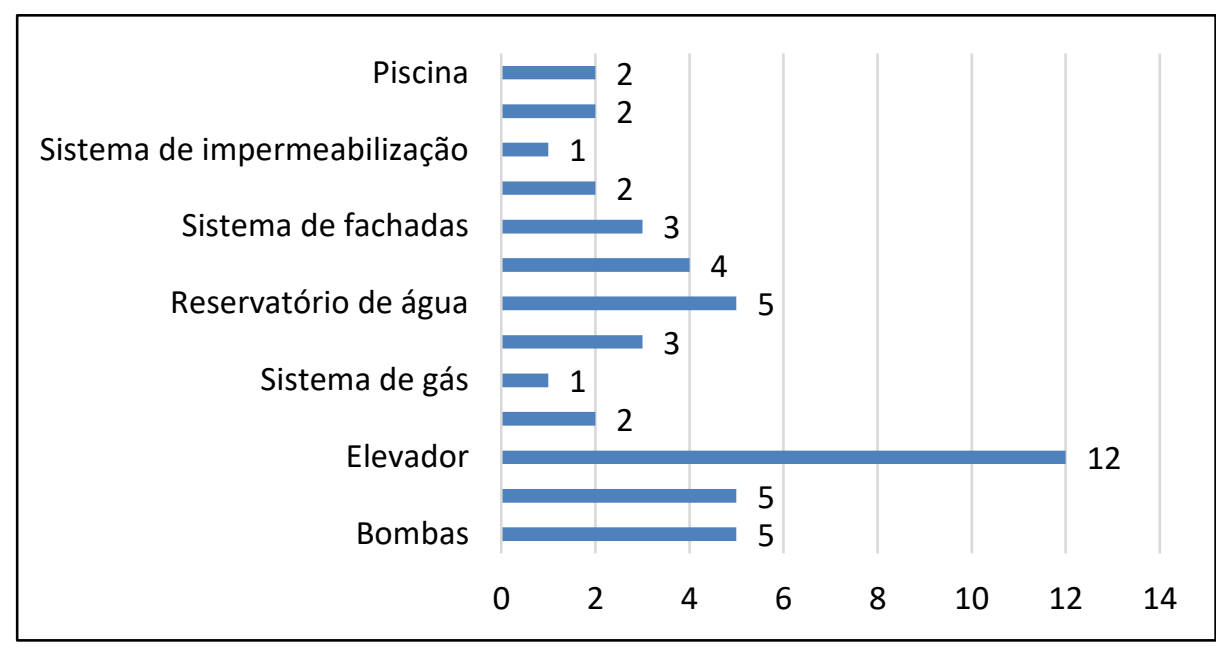

A pergunta seguinte

abordou sobre as principais manifestações patológicas identificadas no condomínio, e com o intuito de receber as mais variadas respostas, essa pergunta foi feita de forma aberta. As respostas mais indicadas pelos respondentes foram problemas nas fachadas, problemas nas instalações, infiltrações e problemas estruturais, conforme o Gráfico 5. Ressalta-se que nenhum desses sistemas foi indicado como os que possuem manutenção preventiva. A ausência de manutenção talvez explique o fato de os mesmos apresentarem manifestações patológicas.

Gráfico 5 - Manifestações patológicas identificadas nas edificações

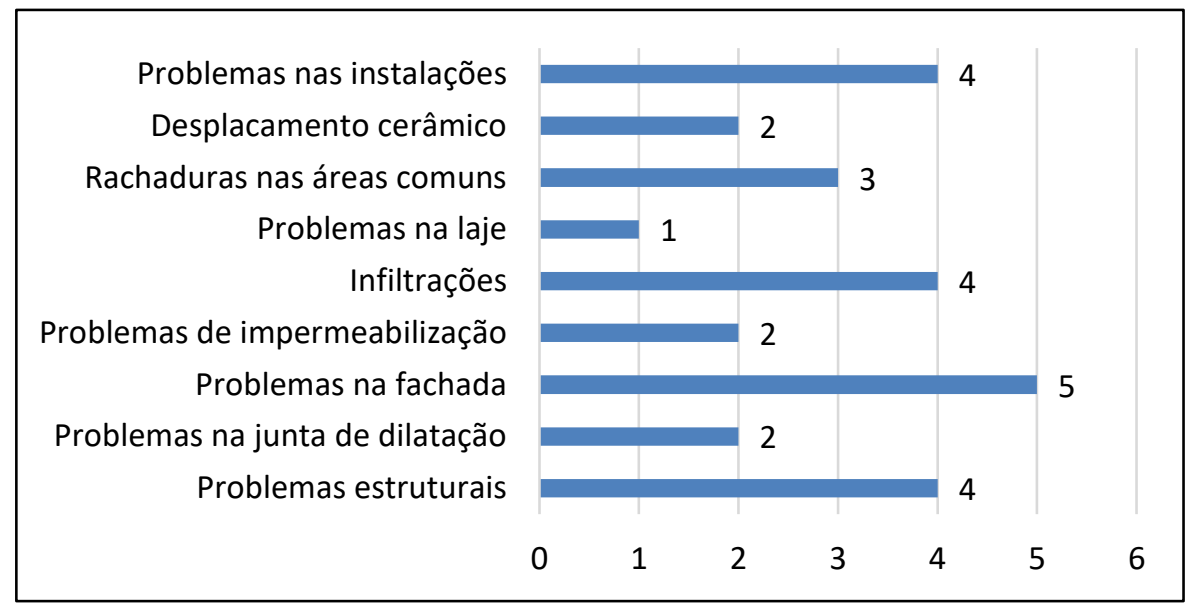

\section{2 - Repostas entrevista com empresas de inspeção predial}

Ao serem questionados sobre as condições estruturais dos condomínios que a empresa realiza serviços a Empresa A relatou essas condições estruturais dividindo seu relato por bairros. No bairro Praia do Futuro, por exemplo, $99 \%$ das edificações estão com problemas sérios na estrutura sem condições de moradia, só possuem moradores que não tem condições de morar em outro local. Na área nobre, em bairros como Aldeota, Meireles e Cocó, problemas como o da Praia do Futuro são menos encontrados, mas quando detectados logo são resolvidos. Ja área litorânea, próximo a avenida Beira Mar, a parte estrutural dos prédios são boas, ocorrem poucos problemas, que só aparecem no decorrer do tempo. No bairro Centro a maioria das edificações estão em condições precárias na parte estrutural e elétrica.

Já a empresa $B$ relatou que normalmente encontram-se problemas estruturais, em edificações com mais de 30 anos, exemplos de problemas são os de ferragem exposta, principalmente ferragens da laje dos banheiros, outros problemas encontrados foram em pilares de subsolo ou pilotis que são juntos com o pavimento. Também relatou que fez serviços em prédios com a estrutura sem problemas, que necessitam de manutenção na parte elétrica por exemplo.

Ao serem questionados sobre os tipos de manifestações patológicas mais identificadas nos laudos a Empresa A identificou problemas no cobrimento mínimo da laje, que muitas vezes nem possuem, no pilar e na viga ocorrem problemas de rachadura, muitas vezes causadas por expansão das armaduras, problemas de 
carbonatação. O problema mais sério resolvido foi o caso de uma fundação, na qual ocorria recalque e que as manifestaçãoes patológicas provenientes dele já estavam em estágio avançado. Já a Empresa B identificou manifestações patologicas nas partes estruturais, de infiltração, na parte elétrica ocorrem problemas nos quadros elétricos e disjuntores que são antigos, fissuras na alvenaria, nas juntas de dilatação de fachada, queda de cerâmica.

Quando questionados sobre os condomínios que possuem o manual de manutenção a Empresa A relatou que a maior parte das edificações não possuem e a maioria dos síndicos nem sabem o que é manual de manutenção. Já a Empresa B relatou que nenhum dos condomínios apresentou manual de manutenção, alguns condomínios recentes podem apresentar o manual simplificado, sem ser detalhado quanto aos serviços de manutenção realizados.

Ao serem questionados sobre os condomínios que prestaram serviços necessitaram de grandes reparos a Empresa A relatou que nas edificações necessitam de muitos reparos, pois ocorrem problemas como recalques de fundação, carbonatação e rachaduras em pilares e vigas, cobrimento de laje insuficiente, fiações e pontos de tomada corroídas pelo efeito da maresia, deslocamento cerâmico de fachada e pisos, entre outros.

A Empresa B relatou que nas edificações precisavam de reparos principalmente na parte estrutural, como por exemplo recuperação das lajes de banheiro; recuperação de caixa d'água, pois estas possuíam suas ferragens comprometidas; problemas na platibanda da parte de coberta e a Empresa B ainda comentou que sempre tem também muito serviço nas fachadas das edificações.

Quando questionados sobre as negligências cometidas pela administração dos condomínios a Empresa $A$ relatou que as edificações classe média/baixa os síndicos procuram profissionais habilitados quando os problemas na edificação são graves. Que edificações antigas, com mais de 30 anos, que não passaram pelas exigências da lei de inspeção predial geralmente possuem alto custo de manutenção, com o sindico optando por engavetar laudos técnicos por justamente ser inviável financeiramente ao condomínio. Relatou que poucos condomínios possuem todos os projetos mínimos exigidos, a maioria não possui os projetos de SPDA, combate a incêndio e estrutural.

Relatou que a manutenção preventiva não é seguida com rigor pelos síndicos e condôminos. Relatou também que a mentalidade dos síndicos tem mudado nos últimos três anos, principalmente depois do desabamento do edifício Andrea, antes desse ocorrido muitos condomínios contratavam profissionais não habilitados, por justamente cobrarem menores preços pelo serviço, para manutenções principalmente nas partes estruturais e elétricas. Já a Empresa $B$ relatou que ocorrem negligências nas partes de fachada e recuperação estrutural das edificações, porque são obras caras.

Quando questionados sobre terem identificado reformas fora do padrão a Empresa A relatou que já foi chamada para realizar serviços em edificações de pequeno porte, de cinco pavimentos, onde a solicitação foi fazer um sexto pavimento. Foram encontrados condomínios com fiações elétricas fora dos padrões de projetos, recuperação estrutural com argamassa impropria para o local, entre outras reformas fora do padrão.

Já a Empresa B relatou que já encontrou muitas reformas fora do padrão em diversos sistemas, os principais são os sistemas de fachada e estrutura. Nesses sistemas, principalmente nas estruturas, os administradores contratam para serviços pedreiros, por cobrarem preços abaixo do mercado, o que torna a segurança e o padrão do serviço insatisfatórios.

\section{Conclusões}

Com base nos resultados obtidos por meio desta pesquisa observou-se que a maioria dos condomínios entrevistados não possuem o manual do proprietário pois foram entregues antes da vigência da norma NBR 14037: Manual de Uso, Operação e Manutenção (ABNT, 2011). Em consequência disso, a maioria não possui plano de manutenção o que pode levar a uma ausência de manutenção ou uma manutenção precária das edificações.

De acordo com os engenheiros entrevistados, as manifestações mais recorrentes são as relacionadas as estruturas e fachadas. Isso corrobora com os últimos acidentes na cidade de Fortaleza - CE envolvendo 
problemas estruturais assim como as várias fachadas de edifícios que podem ser identificadas com problemas pela cidade. Somando-se a isso observou-se que nas respostas obtidas para o terceiro objetivo da pesquisa, no questionário aplicado aos síndicos, foi apontado que as manutenções usuais não são realizadas nas fachadas e na estrutura do edifício, o que pode explicar a grande incidência de problemas nesses sistemas apontada pelos engenheiros das empresas de inspeção predial.

Finalmente, a presente pesquisa mostrou que, na amostra estudada, as normas relacionadas a manutenção ainda são poucos aplicadas e pouco difundidas. Tal fato é preocupante, pois conforme as edificações vão envelhecendo as manutenções se tornam cada vez mais importantes para a durabilidade das estruturas.

Para trabalhos futuros, sugere-se uma pesquisa em maior quantidade de condomínios, assim como dar um foco maior em determinados bairros. Seria interessante também comparar os resultados obtidos com prédios recentes, que foram entregues já seguindo as diretrizes das normas. $O$ intuito seria verificar se o plano de manutenção está sendo entregue e se o condomínio está seguindo as diretrizes do mesmo.

\section{REFERÊNCIAS}

BAMBIRRA, Filipe Starling. Análise de normas técnicas e a elaboração de programa de manutenção predial. Universidade Federal de Minas Gerais, Belo Horizonte, 2019.

BENTO, Adegilson et al. A influência da NBR 15575 (2013) na durabilidade e vida útil das edificações residenciais. Universidade de Pernambuco, Seminário de Patologia e Recuperação Estrutural, Pernambuco, 2016.

BOHN, Thiago Silveira. Elaboração de plano de manutenção predial preventiva de edificação industrial segundo a NBR 5674/2012. Universidade Federal do Rio Grande do Sul, Escola de Engenharia, Departamento de Engenharia Civil, Porto Alegre, 2017.

BOLINA, Fabricio Longhi et al. Patologia de estruturas. Oficina de Textos, São Paulo, 2019.

CARRIJO, Luma Brandão. Laudo técnico de inspeção predial metodologia e prática. 2019. Universidade Federal de Uberlândia, Faculdade de Engenharia Civil, FECIV, Uberlândia - MG, 2019.

CARVALHIAS, Catharina de A. et al. $O$ impacto do custo de recuperação das manifestações patológicas em estruturas de concreto armado. 69 Reunião Anual da SBPC, UFMG, Belo Horizonte - MC, 2017.

CARVALHO, Larissa Cristina de. Inspeção predial: estudo de caso de uma edificação residencial situada em Brasília/DF. Centro Universitário de Brasília, Faculdade de Tecnologia e Ciências Sociais Aplicadas, Brasília, 2019.

CAVALCANTE, Nalyanne Felix et al. Levantamento das manifestações patológicas mais recorrentes nas inspeções prediais em edifícios residenciais de Fortaleza-CE. Curso Engenharia Civil, Centro Universitário Católico de Quixada, 2019.

FEITOSA, André Ayres. Inspeção predial: estudo de caso na cidade de Fortaleza/CE. Universidade Federal do Ceará (UFC), Departamento de Engenharia de Transportes, Engenharia Civil, Fortaleza, 2018.

JARDIM, Maria Tereza M. et al. Manifestações patológicas na construção civil e recuperação de empreendimento de alvenaria pré-moldada: Um Estudo De Caso De Um Empreendimento Localizado No Município De Esmeraldas, Minas Gerais. Minas Gerais: Revista Paramétrica, 2019.

MITZSUZAKI, Caio Yukio Yasuda et al. Patologias na construção civil. Pesquisa e Ação, 2019. 
PEREIRA, Lucas Araújo. Aspectos técnicos e legais em obras de reforma em edificações. Universidade Federal do Rio de Janeiro, Departamento de Construção Civil, Rio de Janeiro, 2017.

PILZ, Silvio E. et al. Avaliação dos métodos de inspeção para atendimento às normas do sistema de gestão predial. Curitiba: Brazilian Journal Of Development, 2019.

POSSAN, E.; DEMOLINER, C. A. Desempenho, durabilidade e vida útil das edificações: abordagem geral. Revista técnico científica do CREA-PR, v. V1, p. 1-18, 2013.

SANCHO, E. S. Leão de Oliveira. Inspeção predial: estudo de caso do museu de arte da universidade federal do Ceará com base na lei 9913/2012 de Fortaleza/CE. Universidade Federal do Ceará, Fortaleza, 2018.

SILVA, Geraldo Oliveira da. Proposta de metodologia de manutenção predial. Centro Universitário de Brasília - UniCEUB, Faculdade de Tecnologia e Ciências Sociais Aplicadas - FATECS, Brasília, 2014.

SOUSA, Eduardo Luz de et al. Paradoxo dos custos da segurança do trabalho na construção civil. Revista Expressão, Sete Lagoas, Minas Gerais 2018.

VERZOLA, Simone Nunes et al. Proposta de lista de verificação para inspeção predial $\mathbf{X}$ urgência das manutenções. XV Encontro Nacional de Tecnologia do Ambiente Construído, ENTAC, 2014. 